\title{
INCREASING CROSS-MARKET CORRELATIONS DURING THE 2007-2009 GLOBAL FINANCIAL CRISIS: CONTAGION OR INTEGRATION EFFECTS?
}

There is no unanimity in the literature regarding the causes of increasing cross-market correlations in crisis periods. This effect is often justified by the authors as a consequence of contagion, but the evidence is that contagion can be confused with the integration effect since both have a tendency to increase correlations among markets, especially during down-market periods. The main goal of this paper is to examine the effect of increasing cross-market correlations during the 2007-2009 global financial crisis on the largest European stock markets (i.e. the U.K., France and Germany), in the context of the influence of the 2007 U.S. subprime crisis. The crisis periods are formally established based on the statistical method of dividing market states into bullish and bearish markets. The evaluation of contagion is carried out by applying both standard contemporaneous cross-market correlations and volatilityadjusted cross-correlations (Forbes, Rigobon 2002). The results are consistent with the literature and confirm that heteroskedasticity in market returns biases tests for contagion based on correlation. Moreover, an integration test is performed using the Larntz-Perlman (1985) procedure for testing the equality of correlation matrices computed over nonoverlapping subsamples: the pre-crisis and crisis periods in the group of investigated markets. No reason was found to reject the research hypothesis of no integration effect during the recent global crisis. The study might be viewed as a contribution to the debate concerning the causes of increasing cross-market correlations during periods of turmoil.

Keywords: global financial crisis, cross-market correlations, contagion, integration

JEL Classifications: C10, F36, F65, G01, G15, O52

DOI: $10.15611 /$ aoe.2017.2.11

\section{INTRODUCTION}

A number of studies assert that cross-market correlations vary over time, thereby making the benefits of international portfolio choice and diversification questionable. Although there is no unanimity in research regarding the causes of increasing cross-market correlations in crisis periods, the majority of researchers agree that during critical market events, correlations change substantially. Two analytical frameworks exist in the literature side by side.

\footnotetext{
* Białystok University of Technology.

${ }^{* *}$ University of Białystok.
} 
On one hand, the cross-correlation movements are attributed to international stock markets' contagion during crises. On the other hand, the increasing cross-market correlations are coupled with the growing integration of financial markets, especially during bear market periods, e.g. (Bekaert et al. 2005; Brière et al. 2012; Bekaert et al. 2014).

The main goal of this paper is to explicitly test two research hypotheses concerning the increasing cross-market correlations effect during a turbulent period for the major European stock markets (i.e. the U.K., France and Germany). The first hypothesis states that there was no contagion among the U.S. and the largest European stock markets during the 2007-2009 global financial crisis. The second hypothesis states that during the recent global crisis there was no integration effect between the markets mentioned above. The empirical results showed that there was no reason to reject both hypotheses.

The remainder of the paper is organized as follows. Section 2 presents a brief literature review concerning the influence of the 2007 U.S. subprime crisis in the European markets. Section 3 specifies the methodological background of the contagion and integration effects. Section 4 reports the data description and empirical results in the investigated stock markets. Section 5 reviews the main findings and concludes.

\section{THE 2007-2009 GLOBAL FINANCIAL CRISIS IN THE MAJOR EUROPEAN STOCK MARKETS}

The influence and consequences of the 2007 U.S. subprime crisis for both the developed and emerging stock markets in the world have been amply reported in the literature. As the aim of this paper is to examine the effect of increasing cross-market correlations during the 2007-2009 financial crisis in the largest European stock markets (i.e. the U.K., France and Germany), we focus our brief analysis of previous literature on the studies related mostly to the developed economies.

According to the literature, e.g. (Brunnermeier 2009; Claessens et al. 2010) among others, the financial crisis timeline, from the U.S. perspective, was marked by the following events: (1) the increase in subprime delinquency rates in the spring of 2007, (2) the ensuing liquidity crunch in late 2007, (3) the liquidation of Bear Stearns in March 2008, and (4) the failure of Lehman Brothers in September 2008. The U.S. economy officially entered recession following the peak in December 2007, that is in 2008Q1.

Bordo and James (2014) analyzed the European crisis in the context of the history of previous international financial crises and they found some 
striking similarities. However, the authors indicated that the modern financial system has more deeply embedded institutions and looks stronger, but when the cracks appear, the damage is deeper. Brunnermeier (2009) asserted that the 2007-2009 crisis was very close to a classic banking crisis. The crisis transmission through financial and banking channels was very rapid and substantial. Most of the researchers pointed out that the crisis originated in the developed countries, largely in the U.S. and the U.K.. Pisani-Ferry and Sapir (2010) stressed that European banks were particularly vulnerable given the high degree of internationalization in their activities, both within the euro area and outside. Moro (2014) noticed that an important element that largely contributed to the crisis in Europe was the mispricing of the risk by capital markets. Since the start of the global financial crisis, financial markets driven by panic overpriced risk and gave incentives to policymakers to introduce excessive austerity programs. Constâncio (2014) investigated the European Monetary Union states in the context of the recent crisis. The author pointed out that the European countries were immediately affected by the global crisis through at least two channels: (1) a number of European banks had substantial balance sheet exposures to the U.S. housing market, and (2) when the global re-pricing of risk triggered by the U.S. sub-prime crisis occurred, it had serious consequences for local financial stability in the European countries.

As a matter of fact there is no agreement among the researchers in determining the phases of crisis in the European countries, (cf. Bartram, Bodnar 2009; Pisani-Ferry, Sapir 2010; Mishkin 2011). In the literature these periods are usually presented arbitrarily. Therefore in our research the crisis periods on the major European stock markets were formally established based on the paper (Olbrys, Majewska 2014a), in which the Pagan and Sossounov (2003) method for direct statistical identification of market states was employed. The Pagan-Sossounov procedure enabled us to identify cycles in equity prices. The empirical results indicated that October 2007-February 2009 was the common crisis period for the New York and London stock markets. The crisis for the Frankfurt stock exchange was shorter and it lasted from December 2007 to February 2009, while for the Paris stock market it was longer and lasted from May 2007 to February 2009. The results confirmed February 2009 as the end of bear markets in all the countries under study.

Figure 1 presents overall information about the U.S. and the major European down market periods in the context of the influence of the 2007 U.S. subprime financial crisis. The periods are: (1) October 2007-February 


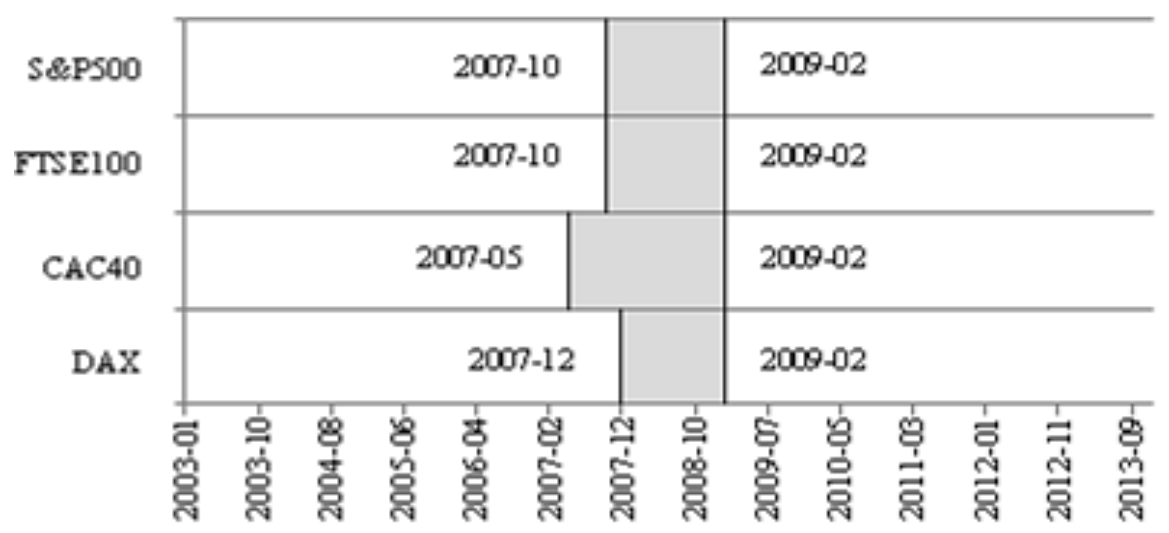

Figure 1. Overall information about the U.S. and the major European down-market periods

Source: own elaboration based on (Olbrys, Majewska 2014a)

2009 for the S\&P500 (New York), (2) October 2007-February 2009 for the FTSE100 (London), (3) May 2007-February 2009 for the CAC40 (Paris), and (4) December 2007-February 2009 for the DAX (Frankfurt).

\section{EVIDENCE OF INCREASING CROSS-MARKET CORRELATIONS DURING CRISES}

As pointed out earlier, international stock market correlations have been widely studied. For example, Longin and Solnik (2001) investigated the conditional correlation structure of international equity returns for five countries: the U.S., the U.K., France, Germany and Japan, in the period January 1959-December 1996. They found that conditional correlation increases in bear markets, but not in bull markets. Campbell et al. (2002) studied the major indexes of the stock markets in the U.S., the U.K., France and Germany in the period May 1990-December 1999. They found evidence of significantly increased correlation in international equity returns in bear markets. Büttner and Hayo (2011) analyzed the determinants of stock market integration among the European Union member states and they applied DCCMGARCH models to extract the dynamic conditional correlations between the European markets. Goetzmann et al. (2005) explored the correlation structure of the major world markets over 150 years. They concluded that international equity correlations change substantially through time. 
It is pertinent to note that high and asymmetric cross-market correlations have important negative aspects because of their practical implications. Firstly, they thwart the investors' striving for international portfolio diversification in crises. Secondly, the asymmetry effect, i.e. a significant increase in international cross-correlations in bear markets compared to bull markets, additionally makes portfolio diversification especially difficult and questionable (Olbrys, Majewska 2015). Although this issue has been amply reported in the literature, there is no unanimity in research regarding the causes of increasing cross-market correlations during periods of turmoil.

\subsection{Contagion Tests}

As mentioned in the introduction, the effect of increasing cross-market correlations in crisis periods is often justified by the authors as the consequence of contagion, but essentially contagion is not simply revealed by increased correlation of market returns. Among others, Edwards (2000) stressed that contagion has been defined in the economic literature in many different ways, including as any transmission of shocks across countries. He distinguished between three mechanisms through which economic shocks are propagated across countries: (1) global disturbances that affect all (or most) countries in the world; (2) shocks coming from a related country, and (3) all instances not covered by the two previous cases, in which contagion is defined as a residual, and thus as a situation where the extent and magnitude of the international transmission of shocks exceeds what was expected by the market participants. Pericoli and Sbracia (2003) presented five definitions of contagion adopted by the literature and the corresponding measures used in empirical work. However they found that early studies did not always distinguish between contagion and interdependence. The authors stressed that the definitions and measures of contagion work well in the presence of an unambiguous identification of financial crisis. Bekaert et al. (2005) defined contagion as excess correlation, that is, correlation over and above what one would expect from economic fundamentals. They engaged contagion from an asset pricing perspective and they expressed it by the correlation of the factor model residuals. Dungey et al. (2005) asserted that the range of different methodologies of testing for the existence of contagion makes it difficult to assess the evidence for and against contagion.

As argued by Rigobon (2002) "(...) there is no accordance on what contagion means". In this vein, Forbes and Rigobon (2002) defined contagion as a significant increase in cross-market linkages after a shock to 
one country (or group of countries), but they stated that this definition is not universally accepted. They stressed that heteroskedasticity in market returns biases tests for contagion based on correlation and correlation coefficients are conditional on market volatility, and therefore they proposed the following correction for the volatility bias:

$$
\hat{\rho}_{V A}=\frac{\hat{\rho}_{C}}{\sqrt{1+\delta\left[1-\left(\hat{\rho}_{C}\right)^{2}\right]}},
$$

where $\hat{\rho}_{V A}$ is the volatility-adjusted cross-correlation coefficient between markets, $\hat{\rho}_{C}$ is the estimated conditional cross-correlation coefficient in the crisis period, and $\delta$ is the relative increase in the variance of market returns in the crisis period compared to the pre-crisis period:

$$
\delta=\frac{\hat{\sigma}_{C}^{2}}{\hat{\sigma}_{P C}^{2}}-1
$$

where $\hat{\sigma}_{C}^{2}, \hat{\sigma}_{P C}^{2}$ are the variances in the high-volatility (crisis) and lowvolatility (pre-crisis) periods, respectively. By construction, it is obvious that $\hat{\sigma}_{C}^{2} \geq \hat{\sigma}_{P C}^{2}$, hence $\delta \geq 0$ and $\hat{\rho}_{V A} \leq \hat{\rho}_{C}$, that is, during the periods of high volatility the unconditional volatility-adjusted cross-correlation $\hat{\rho}_{V A}$ will be smaller than the estimated conditional cross-correlation $\hat{\rho}_{C}$ between markets. The evaluation of contagion is carried out by testing the hypotheses:

$$
\begin{aligned}
& H_{0}: \rho_{V A}=\rho_{P C}, \\
& H_{1}: \rho_{V A} \neq \rho_{P C}
\end{aligned}
$$

where $\rho_{P C}$ is the cross-correlation coefficient in the pre-crisis period and the null hypothesis states that there is no contagion. The $Z$-statistic, which is asymptotically a standard normal random variable, tests null of no contagion, that is, the equality of the crisis with pre-crisis cross-market correlation coefficients. The test is performed with the Fisher (1921) $z$-transformation of sample correlation coefficients. If the absolute value of the $Z$-statistic is greater than the critical value, the null hypothesis of identical correlation coefficients can be rejected (Olbrys, Majewska 2014b). 


\subsection{Integration Tests}

According to the literature, the evidence is that contagion can be confused with market integration since both have a tendency to increase correlations among markets, especially during down market periods. Growing international integration could lead to a progressive increase in market correlations, and markets could be more correlated in periods of high volatility (Longin, Solnik 1995, p. 6). Bekaert et al. (2005) pointed out that integration can be global or regional. To address this issue, we employed a test interpreted as an integration test in the group of the European and the U.S. stock markets investigated using a formal procedure for testing the equality of correlation matrices computed over non-overlapping subsamples, e.g. (Jennrich 1970; Larntz, Perlman 1985; Longin, Solnik 1995; Chesnay, Jondeau 2001; Goetzmann et al. 2005; Brière et al. 2012).

The evaluation of integration is carried out by testing the hypotheses:

$$
\begin{aligned}
& H_{0}: P_{C}=P_{P C}, \\
& H_{1}: P_{C} \neq P_{P C}
\end{aligned}
$$

where $P_{C}, P_{P C}$ are true (population) correlation matrices in the crisis and precrisis periods, respectively, and the null hypothesis states that there is no integration effect during crises.

Different test statistics have been proposed in the literature to test the problem (4). One of the most popular is the test introduced by Jennrich (1970), but Larntz and Perlman (1985) pointed out that this test is basically a large sample test and can perform poorly for small samples. They proposed a test statistic $T_{L P}$ which determined a test with reasonable small sample properties and with power comparable to that of the Jennrich test for large samples (Larntz, Perlman 1985, p. 3). The basic idea is to apply the Fisher (1921) $z$-transformation to each sample correlation coefficient in the correlation matrices $\hat{P}_{C}=\left(\hat{\rho}_{i j}^{C}\right)$ and $\hat{P}_{P C}=\left(\hat{\rho}_{i j}^{P C}\right)$, and to consider the $\frac{p(p-1)}{2}$ dimensional random column vectors consisting of the off-diagonal $z-$ transformations $(1 \leq i<j \leq p)$ arranged in lexicographic order. In the case of two subsamples of equal size $n_{C}=n_{P C}=n$, we use the following version of the Larntz and Perlman (1985) test statistic $T_{L P}$ :

$$
T_{L P}=\sqrt{\frac{n-3}{2}} \times \max _{1 \leq i<j \leq p}\left|z_{i j}^{C}-z_{i j}^{P C}\right|,
$$


where $z_{i j}^{C}$ and $z_{i j}^{P C}$ are the Fisher $z$-transformations of sample correlation coefficients $\hat{\rho}_{i j}^{C}$ and $\hat{\rho}_{i j}^{P C}$, respectively. Larntz and Perlman propose the significance level $\alpha$ test under which the null (4) is rejected if $T_{L P}>b_{\alpha}$, where $b_{\alpha}>0$ is chosen such that $\left[\Phi\left(b_{\alpha}\right)-\Phi\left(-b_{\alpha}\right)\right]^{p(p-1) / 2}=1-\alpha$, and $\Phi$ is the cumulative distribution function of the standard normal distribution.

Based on the cases studied, Larntz and Perlman propose the following rule-of-thumb: when the ratio of sample size to dimension does not exceed 4, i.e. when $n / p \leq 4$, then the $T_{L P}$ test statistic (5) is recommended (Larntz, Perlman 1985, p. 9).

\section{DATA DESCRIPTION AND EMPIRICAL RESULTS}

The data consists of monthly logarithmic returns of three major European stock market indexes: FTSE100 (London), CAC40 (Paris), DAX (Frankfurt) and the New York market index-S\&P500. There are 132 observations for each series for the period beginning January 2003 and ending December 2013. All analyses are conducted using the open-source computer software Gretl 1.9.14 (Adkins 2014).

\subsection{Preliminary Statistics}

Table 1 contains brief information about the major European stock market indexes and the S\&P500 index, in order of decreasing value of market capitalization at the end of 2011.

Table 1

The stock market indexes used in the study

\begin{tabular}{c|c|c|c}
\hline & Market & Market Cap., EUR billion, Dec 2011 & Index \\
\hline 1 & New York & 9126.6 & S\&P500 \\
\hline 2 & London & 2527.3 & FTSE100 \\
\hline 3 & Paris & 1197.0 & CAC40 \\
\hline 4 & Frankfurt & 916.5 & DAX \\
\hline
\end{tabular}

Source: [http://www.world-exchanges.org, https://europeanequities.nyx.com].

Table 2 presents summarized statistics for the monthly logarithmic returns for the four indexes used in the study, as well as statistics testing normality. The table is based on all sample observations during the period 
January 2003-December 2013. The test statistic for skewness and excess kurtosis is the conventional $t$-statistic. The Doornik-Hansen test (2008) has a chi-squared distribution if the null hypothesis of normality is true. The numbers in brackets are $p$-values.

The empirical results presented in Table 2 are worth a comment. The measure for skewness shows that all return series are skewed. The measure for excess kurtosis demonstrates that almost all series are highly leptokurtic with respect to the normal distribution, except for the CAC40 series. The Doornik-Hansen (2008) test rejects normality for each of the return series at the 5 per cent level of significance, but the test does not reject normality for the CAC40 series at the 1 per cent level of significance.

Table 2

Summarized statistics for monthly logarithmic returns for the stock market indexes used in the study

\begin{tabular}{c|c|c|c|c|c|c}
\hline & Index & Mean & $\begin{array}{c}\text { Standard } \\
\text { deviation }\end{array}$ & Skewness & $\begin{array}{c}\text { Excess } \\
\text { kurtosis }\end{array}$ & $\begin{array}{c}\text { Doornik-Hansen } \\
\text { test }\end{array}$ \\
\hline 1 & S\&P500 & 0.006 & 0.042 & $\begin{array}{c}-1.072 \\
{[0.000]}\end{array}$ & $2.916[0.000]$ & $20.083[0.000]$ \\
\hline 2 & FTSE100 & 0.004 & 0.040 & $\begin{array}{c}-0.794 \\
{[0.000]}\end{array}$ & $1.125[0.009]$ & $12.800[0.002]$ \\
\hline 3 & CAC40 & 0.003 & 0.049 & $\begin{array}{c}-0.638 \\
{[0.003]}\end{array}$ & $0.615[0.151]$ & $8.856[0.012]$ \\
\hline 4 & DAX & 0.009 & 0.056 & $\begin{array}{c}-0.628 \\
{[0.004]}\end{array}$ & $2.529[0.000]$ & $20.109[0.000]$ \\
\hline
\end{tabular}

Source: authors' calculations.

\subsection{Cross-Market Correlations in the Context of Contagion}

This subsection presents the empirical results of the verification procedure of the first research hypothesis of no contagion among the U.S. and the largest European stock markets during the 2007-2009 global financial crisis. Based on Figure 1, we advocate December 2007-February 2009 as the common crisis period for all the markets investigated.

Table 3 contains standard contemporaneous cross-market correlations and volatility-adjusted cross-correlation coefficients, given by (1), of monthly logarithmic returns on pairs of the indexes S\&P500/stock market index. For comparison, we calculate dependencies both in the whole sample (January 2003-December 2013) and in two subsamples of equal size: (1) the pre-crisis period September 2006-November 2007 (15 months), and (2) the crisis period December 2007-February 2009 (15 months). We investigate the cross-market linkages after the shock to the U.S. financial market. The supporting values are 
equal to: $\hat{\sigma}_{C}^{2}=0.00389$ (the variance in the high-volatility period in the U.S. stock market) and $\hat{\sigma}_{P C}^{2}=0.00068$ (the variance in the low-volatility period in the U.S. stock market), while the relative increase in the variance of the S\&P500 returns, given by (2), is equal to $\delta=4.718$.

The results confirm that during the crisis period, the estimated contemporaneous cross-correlations between the U.S. and other markets were greater than the corresponding cross-correlations in the pre-crisis period, but the changes were small. As for the volatility-adjusted crosscorrelations one can observe that the Forbes-Rigobon (2002) correction seems to be a rather strong tool for adjusting cross-market correlations for all the markets under study. Assuming the U.S. financial market as a source of risk and using the coefficient $\delta$ of the relative increase in the variance of the S\&P500 returns in the crisis compared to the pre-crisis period, we get a substantial reduction of the value of correlation. As a result, the volatilityadjusted cross-correlations in the crisis period are lower compared to the pre-crisis period for all the countries investigated. To sum up, no reason to reject the null hypothesis (3) was found for all investigated markets.

Table 3

Contemporaneous cross-correlations and volatility-adjusted cross-correlations of monthly logarithmic returns on pairs S\&P500/ stock market index

\begin{tabular}{|c|c|c|c|c|c|c|c|c|c|c|c|}
\hline & \multirow{3}{*}{ Index } & \multicolumn{6}{|c|}{ Contemporaneous cross-correlations } & \multicolumn{4}{|c|}{$\begin{array}{c}\text { Volatility-adjusted cross- } \\
\text { correlations }\end{array}$} \\
\hline & & $\begin{array}{l}\text { Whole } \\
\text { sample }\end{array}$ & $\begin{array}{c}\text { Pre- } \\
\text { crisis (2) }\end{array}$ & \multicolumn{4}{|c|}{ Crisis (3) } & \multicolumn{4}{|c|}{ Crisis (3) } \\
\hline & & $\hat{\rho}$ & $\hat{\rho}_{P C}$ & $\hat{\rho}_{C}$ & $\begin{array}{c}\text { Change } \\
\text { compared } \\
\text { to the } \\
\text { period (2) }\end{array}$ & 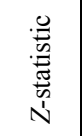 & 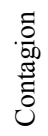 & $\hat{\rho}_{V A}$ & $\begin{array}{l}\text { Change } \\
\text { compared } \\
\text { to the } \\
\text { period (2) }\end{array}$ & 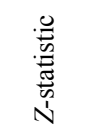 & 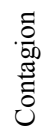 \\
\hline 1 & FTSE100 & $\begin{array}{c}0.849 \\
{[0.000]}\end{array}$ & $\begin{array}{c}0.791 \\
{[0.000]}\end{array}$ & $\begin{array}{c}0.843 \\
{[0.000]}\end{array}$ & $\uparrow 6.57 \%$ & 0.416 & $H_{0}$ & 0.548 & $\downarrow 30.7 \%$ & -1.213 & $H_{0}$ \\
\hline 2 & CAC40 & $\begin{array}{c}0.849 \\
{[0.000]}\end{array}$ & $\begin{array}{c}0.809 \\
{[0.000]}\end{array}$ & $\begin{array}{c}0.901 \\
{[0.000]}\end{array}$ & $\uparrow 11.37 \%$ & 0.935 & $H_{0}$ & 0.656 & $\downarrow 18.9 \%$ & -0.896 & $H_{0}$ \\
\hline 3 & DAX & $\begin{array}{c}0.821 \\
{[0.000]}\end{array}$ & $\begin{array}{c}0.839 \\
{[0.000]}\end{array}$ & $\begin{array}{c}0.890 \\
{[0.000]}\end{array}$ & $\uparrow 6.08 \%$ & 0.540 & $H_{0}$ & 0.632 & $\downarrow 24.6 \%$ & -1.250 & $H_{0}$ \\
\hline
\end{tabular}

Notes: The table is based on: (1) the whole sample period January 2003-December 2013 (132 months); (2) the pre-crisis period September 2006-November 2007 (15 months); (3) the crisis period December 2007-February 2009 (15 months). The numbers in brackets are $p$-values. Fisher $Z$-statistic (1921) tests null of no contagion. The Student's $t$ critical value is 1.711 (at the $10 \%$ significance level)

Source: authors' calculations. 


\subsection{Empirical Results of Integration Test}

The second research hypothesis states that there was no integration effect between the U.S. and the largest European stock markets during the 2007-2009 crisis. In the verification process of this hypothesis we used the LarntzPerlman (1985) procedure for testing the equality of correlation matrices computed over non-overlapping subsamples: the pre-crisis and crisis periods, in the group of markets investigated. In their seminal work, Longin and Solnik (1995) asserted that the covariance/correlation matrix of international asset returns plays a special role in the finance literature as knowledge about its behavior is crucial for the computation of trading portfolios.

Tables 4-6 show all cross-market correlations computed over the whole sample period (Table 4), the pre-crisis period (Table 5), and the crisis period (Table 6). The numbers in brackets are $\mathrm{p}$-values. All coefficients are statistically significant at the 5 per cent level. The evidence is that the level of interdependence between the markets is very high in all periods. As a matter of fact, this is rather unsurprising taking into consideration that the creation of a single market for financial services produced conditions for greater consolidation and internationalization in European Union banking (Pisani-Ferry, Sapir 2010).

Table 4

The correlation matrix, whole sample period January 2003-December 2013

\begin{tabular}{c|c|c|c|c}
\hline Index & S\&P500 & FTSE100 & CAC40 & DAX \\
\hline S\&P500 & 1 & $0.849[0.000]$ & $0.849[0.000]$ & $0.821[0.000]$ \\
\hline FTSE100 & & 1 & $0.873[0.000]$ & $0.804[0.000]$ \\
\hline CAC40 & & & 1 & $0.909[0.000]$ \\
\hline DAX & & & & 1 \\
\hline
\end{tabular}

Source: authors' calculations.

Table 5

The correlation matrix, pre-crisis period September 2006-November 2007

\begin{tabular}{c|c|c|c|c}
\hline Index & S\&P500 & FTSE100 & CAC40 & DAX \\
\hline S\&P500 & 1 & $0.791[0.000]$ & $0.809[0.000]$ & $0.839[0.000]$ \\
\hline FTSE100 & & 1 & $0.860[0.000]$ & $0.820[0.000]$ \\
\hline CAC40 & & & 1 & $0.939[0.000]$ \\
\hline DAX & & & & 1 \\
\hline
\end{tabular}

Source: authors' calculations. 
Table 6

The correlation matrix, crisis period December 2007-February 2009

\begin{tabular}{c|c|c|c|c}
\hline Index & S\&P500 & FTSE100 & CAC40 & DAX \\
\hline S\&P500 & 1 & $0.843[0.000]$ & $0.901[0.000]$ & $0.890[0.000]$ \\
\hline FTSE100 & & 1 & $0.902[0.000]$ & $0.870[0.000]$ \\
\hline CAC40 & & & 1 & $0.953[0.000]$ \\
\hline DAX & & & & 1 \\
\hline
\end{tabular}

Source: authors' calculations.

Table 7 summarizes the integration test performed on the whole group containing the S\&P500 and the three major indexes of the European stock markets.

Table 7

Results of the Larntz-Perlman (1985) integration test

\begin{tabular}{|c|c|c|c|c|c|}
\hline \multirow[b]{2}{*}{ Test periods } & \multicolumn{5}{|c|}{ Larntz-Perlman test } \\
\hline & \multirow{2}{*}{$\begin{array}{c}\text { Test statistic } \\
T_{L P} \\
\\
0.864\end{array}$} & \multicolumn{2}{|c|}{$\begin{array}{c}b_{\alpha} \text { critical value } \\
(5 \%)\end{array}$} & \multicolumn{2}{|c|}{$\begin{array}{c}b_{\alpha} \text { critical value } \\
(10 \%)\end{array}$} \\
\hline $\begin{array}{l}\text { Sept 2006-Nov } 2007 \\
\& \\
\text { Dec 2007-Feb } 2009\end{array}$ & & 2.63 & $H_{0}$ & 2.38 & $H_{0}$ \\
\hline
\end{tabular}

Source: authors' calculations.

The table contains the Larntz-Perlman test statistic, given by (5). The statistic tests the null of no integration. The number of variables $p=4$. The empirical results indicate no reason to reject the null hypothesis (4) which states that the correlation matrix is constant over two adjacent sub-periods: (1) the pre-crisis period September 2006-November 2007 (15 months), and (2) the crisis period December 2007-February 2009 (15 months).

\section{CONCLUSION}

The purpose of this paper was to test two research hypotheses concerning the increasing cross-market correlations effect during the crisis period for the major European stock markets. The first hypothesis states that there was no contagion among the U.S. and the largest European stock markets during the 2007-2009 financial crisis. The second hypothesis states that there was no integration effect between these markets during the recent global financial 
crisis. The empirical results confirm no reason to reject both hypotheses. As for the first hypothesis, the results are rather consistent with the literature, e.g. (Forbes, Rigobon 2002). As for the second hypothesis, the results are essentially not surprising if we take into account that the major European and the U.S. financial markets are always strongly connected, not only during financial crises. This evidence is also in accordance with theoreticians' and practitioners' intuition. As Mishkin (2011) stressed, the crisis started in 2007 in one small part of the financial system, but led to worldwide economic conflagration by late 2008 and early 2009. This revealed that the global financial system is far more interconnected than was previously recognized. Moreover, the results presented by Büttner and Hayo (2011) among others, confirmed that in general the impact of European political integration on financial market integration is stronger than the evidence for the influence of macroeconomic factors. Furthermore, it is rather obvious that the European countries are strongly heterogeneous in many aspects. For example, Moro (2014) pointed out that, in fact, Germany is the only country in the European Union that can expand its aggregate demand without paying a substantial increase in domestic inflation.

This study might be viewed as a contribution to the debate concerning the causes of increasing cross-market correlations during periods of turmoil. We are aware of the fact that our analysis cannot provide definitive conclusions regarding these causes. Due to the importance of the problem, a possible direction for further investigation would be to test for the integration effect applying international asset pricing models, e.g. (Bekaert et al. 2005; Hardouvelis et al. 2006; Bekaert et al. 2014). Another important direction would be to recognize the dynamics of financial integration across the European stock markets following for example the methodology introduced by Volosovych $(2011,2013)$.

\section{REFERENCES}

Adkins, L.C., Using Gretl for Principles of Econometrics, 4th Ed., Version 1.041, 2014.

Bartram, S. M., Bodnar, G., No Place to Hide: The Global Crisis in Equity Markets in 2008/2009, "Journal of International Money and Finance”, 28(8), pp. 1246-1292, 2009.

Bekaert, G., Harvey, C. R., Ng, A., Market Integration and Contagion, "Journal of Business", 78,(1), pp. 39-69, 2005.

Bekaert, G., Ehrmann, M., Fratzscher, M., Mehl, A., The Global Crisis and Equity Market Contagion, Working Paper No. 1352, DIW Berlin, 2014. 
Bordo, M., James, H., The European Crisis in the Context of the History of Previous Financial Crises, "Journal of Macroeconomics", 39, pp. 275-284, 2014.

Brière, M., Chapelle, A., Szafarz, A., No Contagion, only Globalization and Flight to Quality, "Journal of International Money and Finance", 31, pp. 1729-1744, 2012.

Brunnermeier, M. K., Deciphering the Liquidity and Credit Crunch 2007-2008, "Journal of Economic Perspectives", 23(1), pp. 77-100, 2009.

Büttner, D., Hayo, B., Determinants of European Stock Market Integration, "Economic Systems", 35, pp. 574-585, 2011.

Campbell, J. Y., Koedijk, K., Kofman, P., Increased Correlation in Bear Markets, "Financial Analysts Journal", 58(1), pp. 87-94, 2002.

Chesnay, F., Jondeau, E., Does Correlation between Stock Returns Really Increase during Turbulent Periods?, "Economic Notes", 30, pp. 53-80, 2001.

Claessens, S., Dell'Ariccia, G., Igan, D., Laeven, L., Cross-country Experience and Policy Implications from the Global Financial Crisis, "Economic Policy", 62, pp. 267-293, 2010.

Constâncio, V., The European Crisis and the Role of the Financial System, "Journal of Macroeconomics", 39, pp. 250-259, 2014.

Doornik, J. A., Hansen, H., An Omnibus Test for Univariate and Multivariate Normality, "Oxford Bulletin of Economics and Statistics", 70, Supplement 1, pp. 927-939, 2008.

Dungey, M., Fry, R., Gonzales-Hermosillo, B., Martin, V. L., Empirical Modeling of Contagion: A Review of Methodologies, "Quantitative Finance", 5(1), pp. 9-24, 2005.

Edwards, S., Contagion, "World Economy”, 23(7), pp. 873-900, 2000.

Fisher, R. A., On the "Probable Error" of a Coefficient of Correlation Deduced from a Small Sample, "Metron", 1, pp. 3-32, 1921.

Forbes, K. J., Rigobon, R., No Contagion, only Interdependence: Measuring Stock Market Comovements, "Journal of Finance", 57(5), pp. 2223-2261, 2002.

Goetzmann, W. N., Li, L., Rouwenhorst, K. G., Long-term Global Market Correlations, “Journal of Business", 78(1), pp. 1-38, 2005.

Hardouvelis, G. A., Malliaropulos, D., Priestley, R., EMU and European Stock Market Integration, "Journal of Business", 79(1), pp. 365-392, 2006.

Jennrich, R. I., An Asymptotic Chi-Square Test for the Equality of Two Correlation Matrices, "Journal of the American Statistical Association", 65, pp. 904-912, 1970.

Larntz, K., Perlman, M. D., A Simple Test for the Equality of Correlation Matrices. Technical Report No. 63, Department of Statistics, University of Washington, 1985.

Longin, F., Solnik, B., Is the Correlation in International Equity Returns Constant: 1960-1990?, "Journal of International Money and Finance", 14(1), pp. 3-26, 1995.

Longin, F., Solnik, B., Extreme Correlation of International Equity Markets, “Journal of Finance”, 56(2), pp. 649-676, 2001.

Mishkin, F. S., Over the Cliff: From the Subprime to the Global Financial Crisis. "Journal of Economic Perspectives", 25(1), pp. 49-70, 2011.

Moro, B., Lessons from the European Economic and Financial Great Crisis: A Survey, "European Journal of Political Economy", 34, pp. S9-S24, 2014. 
Olbrys, J., Majewska E., Quantitative Identification of Crisis Periods on the Major European Stock Markets, "La Pensée”, 76(1), pp. 254-260, 2014a.

Olbrys, J., Majewska, E., Direct Identification of Crisis Periods on the CEE Stock Markets: The Influence of the 2007 U.S. Subprime Crisis, "Procedia Economics and Finance", 14, pp. 461-470, 2014b.

Olbrys, J., Majewska, E., Bear Market Periods during the 2007-2009 Financial Crisis: Direct Evidence from the Visegrad Countries, "Acta Oeconomica”, 65(4), pp. 547-565, 2015.

Pagan, A. R., Sossounov, K. A., A Simple Framework for Analysing Bull and Bear Markets. "Journal of Applied Econometrics", 18(1), pp. 23-46, 2003.

Pericoli, M., Sbracia, M., A Primer on Financial Contagion, "Journal of Economic Surveys", 17(4), pp. 571-608, 2003.

Pisani-Ferry, J., Sapir, A., Banking Crisis Management in the EU: An Early Assessment, "Economic Policy", 62, pp. 341-373, 2010.

Rigobon, R., Contagion: How to Measure it? [in:] Edwards, S., Frankel, J. A. (eds) Preventing Currency Crises in Emerging Markets. University of Chicago Press, Chicago, 2002.

Volosovych, V., Measuring Financial Market Integration over the Long Run: Is there a U-shape?, "Journal of International Money and Finance", 30, pp. 1535-1561, 2011.

Volosovych, V., Learning about Financial Market Integration from Principal Components Analysis, "CESifo Economic Studies", 59(2), pp. 360-391, 2013.

Received: October 2014, revised: December 2016

Acknowledgements: The contribution of the first named author was supported by the grant S/WI/1/2014 from Bialystok University of Technology and funded from the resources for research by the Ministry of Science and Higher Education. 